\title{
The Caenorhabditis globin gene family reveals extensive nematode-specific radiation and diversification
}

\author{
David Hoogewijs' ${ }^{1}$, Sasha De Henau1 ${ }^{1}$, Sylvia Dewilde ${ }^{2}$, Luc Moens², \\ Marjolein Couvreur ${ }^{3}$, Gaetan Borgonie ${ }^{3}$, Serge N Vinogradov ${ }^{4}$, Scott W Roy ${ }^{5}$ \\ and Jacques R Vanfleteren*1
}

\author{
Address: ${ }^{1}$ Department of Biology and Center for Molecular Phylogeny and Evolution, Ghent University, B-9000 Ghent, Belgium, ${ }^{2}$ Department of \\ Biomedical Sciences, University of Antwerp, B-2610 Antwerp, Belgium, ${ }^{3}$ Department of Biology, Nematology section, Ghent University, 9000 \\ Ghent, Belgium, ${ }^{4}$ Department of Biochemistry and Molecular Biology, Wayne State University School of Medicine, Detroit, Michigan 48201, USA \\ and ${ }^{5}$ National Center for Biotechnology Information, National Library of Medicine, National Institutes of Health, Bethesda, MD 20814, USA \\ Email: David Hoogewijs - David.Hoogewijs@UGent.be; Sasha De Henau - Sasha.DeHenau@UGent.be; \\ Sylvia Dewilde - Sylvia.Dewilde@ua.ac.be; Luc Moens - Luc.Moens@ua.ac.be; Marjolein Couvreur - Marjolein.Couvreur@UGent.be; \\ Gaetan Borgonie - Gaetan.Borgonie@UGent.be; Serge N Vinogradov - svinogra@med.wayne.edu; Scott W Roy - scottwroy@gmail.com; \\ Jacques R Vanfleteren* - Jacques.Vanfleteren@UGent.be \\ * Corresponding author
}

Published: 9 October 2008

BMC Evolutionary Biology 2008, 8:279 doi:10.1/86/147/-2148-8-279

This article is available from: http://www.biomedcentral.com/I47I-2/48/8/279

(C) 2008 Hoogewijs et al; licensee BioMed Central Ltd.

This is an Open Access article distributed under the terms of the Creative Commons Attribution License (http://creativecommons.org/licenses/by/2.0), which permits unrestricted use, distribution, and reproduction in any medium, provided the original work is properly cited.
Received: 3 July 2008

Accepted: 9 October 2008

\begin{abstract}
Background: Globin isoforms with variant properties and functions have been found in the pseudocoel, body wall and cuticle of various nematode species and even in the eyespots of the insect-parasite Mermis nigrescens. In fact, much higher levels of complexity exist, as shown by recent whole genome analysis studies. In silico analysis of the genome of Caenorhabditis elegans revealed an unexpectedly high number of globin genes featuring a remarkable diversity in gene structure, amino acid sequence and expression profiles.

Results: In the present study we have analyzed whole genomic data from $C$. briggsae, $C$. remanei, Pristionchus pacificus and Brugia malayi and EST data from several other nematode species to study the evolutionary history of the nematode globin gene family. We find a high level of conservation of the $C$. elegans globin complement, with even distantly related nematodes harboring orthologs to many Caenorhabditis globins. Bayesian phylogenetic analysis resolves all nematode globins into two distinct globin classes. Analysis of the globin intron-exon structures suggests extensive loss of ancestral introns and gain of new positions in deep nematode ancestors, and mainly loss in the Caenorhabditis lineage. We also show that the Caenorhabditis globin genes are expressed in distinct, mostly non-overlapping, sets of cells and that they are all under strong purifying selection.

Conclusion: Our results enable reconstruction of the evolutionary history of the globin gene family in the nematode phylum. A duplication of an ancestral globin gene occurred before the divergence of the Platyhelminthes and the Nematoda and one of the duplicated genes radiated further in the nematode phylum before the split of the Spirurina and Rhabditina and was followed by further radiation in the lineage leading to Caenorhabditis. The resulting globin genes were subject to processes of subfunctionalization and diversification leading to cell-specific expression patterns. Strong purifying selection subsequently dampened further evolution and facilitated fixation of the duplicated genes in the genome.
\end{abstract}




\section{Background}

Globins are small globular proteins, usually consisting of about 140-150 amino acids that comprise eight $\alpha$-helical segments (named A-H), displaying a characteristic 3-over$3 \alpha$-helical sandwich structure that encloses an iron-containing heme group. Vertebrate globin genes predominantly contain three exons separated by two introns inserted at highly conserved positions B12.2 (intron located between codon positions 2 and 3 of the 12th amino acid of globin helix B) and G7.0 (intron inserted between the codons for amino acids 6 and 7 of helix $G$ ). Organisms can express multiple globin molecules that have variant properties and functions. Vertebrates typically express haemoglobin in red blood cells, myoglobin in muscle, neuroglobin in nervous tissue [1] and cytoglobin in a variety of non-neuronal cells [2]. Invertebrate globins constitute a more heterogeneous group in terms of structure and function. They range from singledomain globins to large, multisubunit, multidomain hemoglobins and can be fused with nonglobin subunits forming chimeric proteins. Besides a conventional $\mathrm{O}_{2}$ storage and transport function, a wealth of diverse functions has been described for invertebrate globins $[3,4]$. Nematodes express distinct globin isoforms in the pseudocoel, body wall and cuticle [5]. The emergence of whole genome analysis tools has revealed even higher levels of complexity. In silico analysis of the C. elegans genome identified 33 putative globin genes in this species using a robust alignment procedure based on conserved structural features of the classical globin fold. These globins feature a wide diversity in gene structure, amino acid sequence and expression profiles. Despite this remarkable variety some of them display significant sequence similarity to vertebrate myoglobin, neuroglobin and cytoglobin [6,7].

The availability of full genomic sequences of two additional Caenorhabditis species presents a unique opportunity to explore the evolutionary globin dynamics of these species. In this study we provide a comprehensive evolutionary analysis of the Caenorhabditis globin gene family and we document that globins are found in a broad range of other nematode species.

\section{Results and discussion \\ Occurrence of globins in the Nematoda}

We identified globin gene sequences and exon-structures from full genomic sequences of five nematodes: the Caenorhabditis species C. elegans, C. briggsae and C. remanei (Rhabditina, Rhabditidae) and the distantly related nematodes Pristionchus pacificus (Rhabditina, Diplogasteromorpha) and Brugia malayi (Spirurina, Spiruromorpha) (Additional file 1). This allows comparison of nematode globins across three levels - ortholog evolution within the Caenorhabditis genus, ortholog evolution across more dis- tantly related nematodes and evolution of paralogous genes.

Ortholog conservation for C. elegans globins varied across levels. We identified clear orthologs of all 33 C. elegans genes in C. briggsae and C. remanei, but reciprocal blast searches with the TBLASTN algorithm [8] and the C. elegans globin amino acid sequences identified only 24 and 13 globins in the genomes of Pristionchus pacificus and Brugia malayi, respectively, reducing the number of orthologs shared by all 5 species to 10 .

By screening NEMBASE [9] we found 103 parasitic globins in several other parasitic nematodes with E-values below $\mathrm{e}^{-05}$. Some matched sequences of already known nematode globins from GenBank, while others lacked parts of the A-or H-helix reducing the total number of different NEMBASE EST clusters to 85 (Table 1). Thus far, we can conclude that globins are present in 31 different nematode species representing 4 nematode clades (I, III, IV and V $[10,11])$. In addition to the species listed in Table 1, partial globin sequences were also detected in Heterodera schachtii, Litomosoides sigmodontis, Meloidogyne chitwoodi and Strongyloides ratti.

\section{Two separate globin classes?}

Overall, we recovered over 120 new globin-like sequences from exhaustive database searches. Globin domains were extracted, aligned (Additional files 2 and 3) and subjected to phylogenetic analysis. Bayesian inference of the globin domains of all 33 C. elegans globins and globins from a representative set of 26 non-Rhabditid, mostly parasitic, species and globins from plants, trematodes and a sea anemone (Nematostella vectensis) as outgroup taxa clearly separated two classes of nematode globins. Class I globins comprises C. elegans ZK637.13, well known globins from other nematode species and novel related nematode globin isoforms as well as the trematode globins and is supported by $100 \%$ posterior probability. Class II globin genes consist of the remaining 32 Caenorhabditis globins and novel orthologs thereof, identified in parasitic nematodes (Figure 1). They form a more diverse clade that is resolved from the sea anemone globins with moderate support $(\mathrm{p}=0.78)$. This pattern was essentially retained, though not satisfactorily supported, when more globins from distantly related eukaryotes were included in the analysis (results not shown). We included the cnidarian and trematode globins in this analysis because a recent phylogenomic analysis resolved the Cnidaria as a sister taxon to the Bilateria and the Lophotrochozoa (comprising the Platyhelminthes) as a sister taxon to the Ecdysoza, to which the Nematoda belong [12]. Thus Bayesian inference seems to indicate that a class II ancestral globin evolved before the divergence of the Platyhelminthes and the Nematoda and radiated further in the nematode phy- 
Table I: Parasitic nematode EST clusters identified in NEMBASE

\begin{tabular}{|c|c|}
\hline species & NEMBASE ID \\
\hline Ancylostoma caninum & ACP00369_I \\
\hline Ancylostoma caninum & ACPOI487_2 \\
\hline Ancylostoma caninum & ACP03829_I \\
\hline Ascaris lumbricoides & ALP00043_I \\
\hline Ascaris suum & ASP00019_I \\
\hline Ascaris suum & ASP00780_I \\
\hline Ascaris suum & ASPI7423_I \\
\hline Ancylostoma ceylanicum & AYP00272_I \\
\hline Ancylostoma ceylanicum & AYP00544_I \\
\hline Ancylostoma ceylanicum & AYP0288I_I \\
\hline Ancylostoma ceylanicum & AYPO1816_I \\
\hline Ancylostoma ceylanicum & AYP03578_I \\
\hline Ancylostoma ceylanicum & AYP03942_I \\
\hline Dirofilaria immiti & DIP00455_I \\
\hline Dirofilaria immitis & DIP00540_I \\
\hline Globodera rostochiensis & GRPOOII5_I \\
\hline Globodera rostochiensis & GRP00048_I \\
\hline Haemonchus contortus & HCP00202_I \\
\hline Haemonchus contortus & HCP00202_2 \\
\hline Haemonchus contortus & HCP00202_3 \\
\hline Haemonchus contortus & HCP00202_4 \\
\hline Haemonchus contortus & HCP00202_5 \\
\hline Haemonchus contortus & HCP00208_I \\
\hline Haemonchus contortus & HCP00208_2 \\
\hline Haemonchus contortus & HCP00333_2 \\
\hline Haemonchus contortus & HCP00759_I \\
\hline Haemonchus contortus & HCP00759_2 \\
\hline Haemonchus contortus & HCP00759_3 \\
\hline Haemonchus contortus & HCP00770_I \\
\hline Haemonchus contortus & HCP00770_2 \\
\hline Haemonchus contortus & HCP00770_3 \\
\hline Haemonchus contortus & HCP00786_I \\
\hline Haemonchus contortus & HCPOI3I4_3 \\
\hline Haemonchus contortus & HCP028I5_I \\
\hline Haemonchus contortus & HCP0850I_I \\
\hline Haemonchus contortus & HCPI3III_I \\
\hline Heterodera glycines & HGP06223_2 \\
\hline Heterodera glycines & HGP00385_I \\
\hline Meloidogyne hapla & MHP02564_2 \\
\hline Meloidogyne hapla & MHP044I2_I \\
\hline Meloidogyne incognita & MIP00586_2 \\
\hline Meloidogyne javanica & MJP04640_I \\
\hline Meloidogyne paranaensis & MPP00429_I \\
\hline Necator americanus & NAP0004I_I \\
\hline Necator americanus & NAP00088_I \\
\hline Nippostrongylus brasiliensis & NBP00095_I \\
\hline Nippostrongylus brasiliensis & NBPO0I24_I \\
\hline Nippostrongylus brasiliensis & NBP00197_I \\
\hline Nippostrongylus brasiliensis & NBP00328_I \\
\hline Ostertagia ostertagi & OOP00190_I \\
\hline Ostertagia ostertagi & OOP00190_2 \\
\hline Ostertagia ostertagi & OOP00214_I \\
\hline Ostertagia ostertagi & OOP03092_2 \\
\hline Ostertagia ostertagi & OOP03348_2 \\
\hline Ostertagia ostertagi & OOP035I3_I \\
\hline Onchocerca volvulus & OVP00634_I \\
\hline Onchocerca volvulus & OVP06929_I \\
\hline Onchocerca volvulus & OVP04040_I \\
\hline
\end{tabular}

lum. Alternative phylogenetic methods, neighbor-joining (MEGA [13]) and maximum likelihood (RAxML [14]), were consistent with Bayesian analysis but statistical support was not significant (data not shown).

The finding that 9 parasite EST's resolve with class II globins feeds our expectation that many more are to be detected as more nematode genome sequences will become available. The phylogenetic trees represented in Figure 2 and Figure 3 clearly illustrate that the divergence of the globin genes preceded species divergence. Also, molecular and species trees (Brugia separates first, followed by Pristionchus and next the Caenorhabdits cluster) agree very well for most globin genes. Of note are the very short branch lengths from the Caenorhabditis ancestor to the three extant species, considering that these species diverged around 100 million year ago [15] (Figure 3). These branch lengths are disproportionally short, relative to the branch lengths generated for Brugia and Pristionchus and even more so to those representing the divergence of the globin genes. A likely explanation is that the rate of evolution of the globin genes drastically slowed down in Caenorhabditis. Alternatively, diversity within Caenorhabditis could represent less of nematode history (i.e. a much more recent divergence) than previously appreciated. To distinguish between these possibilities we explored the rate of evolution of several other gene families including astacins, superoxide dismutases, glutathione S-transferases, nicotinic acetylcholine receptors, hedgehog-related proteins and ATP-binding proteins. We assembled a matrix of as many as possible five-way orthologs for the five taxa and analyzed the resulting matrix by Bayesian inference using partitioning of the data (Additional file 4). The ratios of the branch lengths from Brugia malayi or Pristionchus pacificus to the Caenorhabditis internal node and the average branch length of that node to the extant species suggest that the evolutionary rate is quite variable among gene families (Table 2). However, these results also suggest that four (globins, nicotinic acetylcholine receptors, astacins and hedgehog-related proteins) out of the seven multigene families tested evolved more slowly in the Caenorhabditis lineage.

\section{Tissue-specific expression}

We constructed gene fusions of approx $800-3000$ bp upstream promoter and enhancer regions for all 33 globin genes to the coding region of GFP. Spatial expression patterns were observed for 32 genes. Although we have not yet unambiguously identified the specific cells expressing these genes it is clear that these globins are expressed in distinct, mostly non-overlapping sets of cells. Most globin genes were expressed in neuronal cells in the head and tail portions of the body, and the nerve cord. A minority of the globin genes were expressed in non-neuronal tissues, 
Table I: Parasitic nematode EST clusters identified in NEMBASE (Continued)

\begin{tabular}{cc}
\hline Parastrongyloides trichosuri & PTP03438_I \\
Radophulus similis & RSP00034_I \\
Strongyloides stercoralis & SSP0023I_I \\
Strongyloides stercoralis & SSP00309_I \\
Strongyloides stercoralis & SSP02226_I \\
Strongyloides stercoralis & SSP04285_I \\
Strongyloides stercoralis & SSP04654_I \\
Toxocara canis & TCP00537_I \\
Teladorsagia circumcincta & TDP00008_I \\
Teladorsagia circumcincta & TDP00008_2 \\
Teladorsagia circumcincta & TDP00008_3 \\
Teladorsagia circumcincta & TDP00008_4 \\
Teladorsagia circumcincta & TDP00009_I \\
Teladorsagia circumcincta & TDP00009_2 \\
Teladorsagia circumcincta & TDP00032_I \\
Teladorsagia circumcincta & TDP00084_I \\
Teladorsagia circumcincta & TDP00I27_I \\
Teladorsagia circumcincta & TDP00173_I \\
Teladorsagia circumcincta & TDP0IIII_I \\
Teladorsagia circumcincta & TDP0III3_2 \\
Trichuris muris & TMP00I80_I \\
Trichuris muris & TMP01615_I \\
Trichinella spiralis & TSP03467_I \\
Trichuris vulpis & TVP00077_I \\
Trichuris vulpis & TVP00688_I \\
Xiphinema index & XIP0072I_I \\
Zeldia punctata & ZPP002I8_I \\
\hline
\end{tabular}

Accession numbers correspond to those in NEMBASE.

including body wall and vulval muscle and the pharynx; only one globin gene, C26C6.7 was expressed in muscular tissue exclusively. We never observed GFP expression in the intestine or gonad (Table 3 and Figure 4).

\section{Intron evolution}

Analysis of the gene structures for conserved globin domains for the 10 five-way conserved orthologs revealed striking differences across evolutionary levels (Table 4). Consistent with previous findings (e.g. [16]), most intron positions (23/24) were conserved across Caenorhabditis species. Orthologous gene structures were more diverged between genera, but majorities of positions were shared across genera for each species (17/24 Caenorhabditis positions were also identified in Pristionchus and/or Brugia, 25/48 Pristionchus pacificus insertion positions in Caenorhabditis and/or Brugia, and 23/30 B. malayi positions in Caenorhabditis and/or Pristionchus). To determine the relative contribution of intron loss and gain to these patterns, we used previously published methods $[17,18]$ to reconstruct evolution (Figure 5). Estimated numbers of gains and losses were similar (22 versus 34 ), in stark contrast to patterns observed within Caenorhabditis [19-22]. These reconstructions suggest very different histories in Caenorhabditis (four losses for each gain) and P. pacificus (60\% more gains than losses).
The most striking pattern is seen at the level of divergence between paralogs. In contrast to the generally conserved intron positions of most eukaryotic globins, nematode globins exhibit a tremendous variability in intron positions (Additional file 1). Interestingly, only one Caenorhabditis globin (F21A3.6) displays the typical ancestral intron positions common to vertebrates and other eukaryotes (at positions B12.2 and G7.0), as do the B. malayi and $P$. pacificus orthologs. In addition, the Brugia ortholog of C. elegans globin gene ZK637.13, which has only one intron inserted at E3.2, has B12.2 and G7.0, whereas the Pristionchus ortholog contains B12.2 and G7.0 as well as E3.2. Finally, we found no strong evidence for or against any particular model of intron gain - consistent with the apparent age of the introns (most dating to early nematodes), no clear sequence similarity was observed to other genomic sequences (as expected by transposition of existing introns or intron creation by transposable element insertion) or to flanking exonic sequences (as expected by transformation of duplicated genomic sequence into a new intron). The diversity of globin intron positions in nematodes stands in stark contrast to that observed in some other lineages. For instance, in vertebrates, despite a degree of sequence divergence among paralogous globins comparable to that in nematodes, intron positions are generally conserved. Notably, intron-exon structure of nematode globins follows protein divergence; F21A3.6 is both the only gene to retain both ancestral introns, and shows the highest sequence identity to vertebrate globins (specifically, vertebrate myoglobin; data not shown).

In total, then, nematode globin intron-exon structures suggest a large amount of intron change (loss of ancestral introns and gain of new positions) in deep nematode ancestors, followed by differential loss and gain in individual subsequent lineages, with the Caenorhabditis lineage showing a pronounced excess of loss over gain. These data deepen the mystery of atypical nematode intron evolution (including high rates of loss and gain, frequent trans-splicing, and atypical intron splicing signals).

\section{Mode of selective pressure}

The striking diversity of nematode globins raises the question of the role of natural selection on the evolution of these genes. We determined the ratio of non-synonymous (Ka) to synonymous substitution (Ks) rates for each orthologous briggsae/elegans pair (Table 5). The substitution ratio $(\omega)$ is expected to be near 1 for genes under neutral selection, greater than 1 for genes under positive selection and smaller than 1 for those under negative selection. All $\omega$-ratios ranged from 0.0070 to 0.1876 with an average of 0.0367 , indicating functional constraint. Similar results were found for the orthologous elegans/ remanei (average of 0.0359) and briggsae/remanei $(0.0463$ 


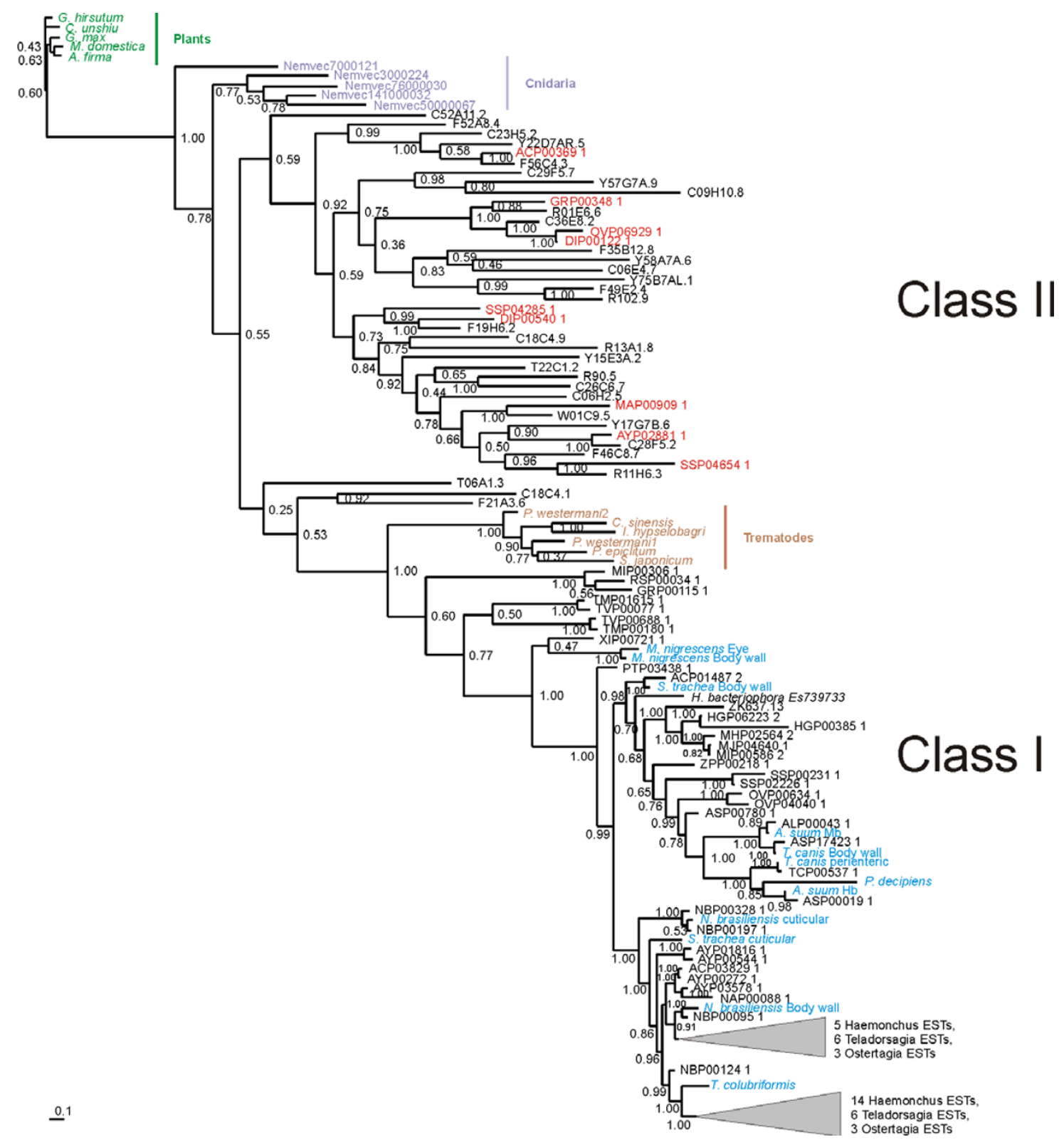

Figure I

Bayesian phylogenetic tree of globins from C. elegans and from $\mathbf{3 0}$ other nematode, predominantly parasitic, species. Orthologs from parasitic species in clade II are marked in red. Clade I globins from parasitic nematodes that have been known for long because of their high abundance are marked in blue. The numbers at the nodes represent Bayesian posterior probabilities. All accession numbers from NEMBASE start with the initials of the species followed by P: Ancylostoma caninum (AC), Ancylostoma ceylanicum (AY), Ascaris lumbricoides (AL), Ascaris suum (AS), Dirofilaria immitis (DI), Globodera rostochiensis (GR), Haemonchus contortus (HC), Heterodera glycines (HG), Meloidogyne chitwoodi (MC), Meloidogyne hapla (MH), Meloidogyne incognita (MI), Meloidogyne javanica (MJ), Necator americanus (NA), Nippostrongylus brasiliensis (NB), Ostertagia ostertagi (OO), Onchocerca volvulus (OV), Parastrongyloides trichosuri (PT), Strongyloides stercoralis (SS), Toxocara canis (TC), Teladorsagia circumcincta (TD), Trichuris muris (TM), Trichinella spiralis (TS), Trichuris vulpis (TV), Xiphinema index (XI), Zeldia punctata (ZP). Plant, trematode (Platyhelminthes) and sea anemone (Cnidaria) globins were included as outgroup globins. The following plant globins (green) were included:Gossypium hirsutum (AAX86687), Malus domestica (AAP57676), Glycine max (AAA97887), Alnus firma (BAE75956), Citrus unshiu (AAK07675). The trematode globins (brown) were: Schistosoma japonicum (AAP062 I6), Paramphistomum epiclitum (AAG48877), Paragonimus westermani (AAXII352 and AAXI I353), Clonorchis sinensis (AAMI8464), Isoparorchis hypselobagri (P80722). Nematostella vectensis globins (purple): Nemvec I 41000032, Nemvec3000224, Nemvec50000067, Nemvec7000I 21 and Nemvec76000030. 
Table 2: Evolutionary distance of seven multigene families of Pristionchus pacificus and Brugia malayi compared to Caenorhabditis, inferred from branch length ratios (Additional file 4). glb globin; gst glutathione S-transferase; ast astacin, sod superoxide dismutase, acr nicotinic acetylcholine receptors; wrt hedgehog-related (warthog) proteins; abc ATP-binding proteins.

\begin{tabular}{cccccccc}
\hline & Glb & gst & sod & ast & wrt & acr & abc \\
\hline B. malayi & 14.10526 & 7.09375 & 7.439024 & 12.15217 & 10.34615 & 17.60357 & 4.163636 \\
P. pacificus & 10.86842 & 5.59375 & 4.182927 & 10.65217 & 11.15385 & 16.96071 & 4.272727 \\
\hline
\end{tabular}

on average) pairs. No substantial differences were obtained when this analysis was applied on the globin domains only (results not shown). All C. elegans globin genes are expressed [7]. Although pseudogenes have been found in C. elegans with $\omega$-ratios down to 0.4 (Ian Hope, personal communication), the combination of these find-

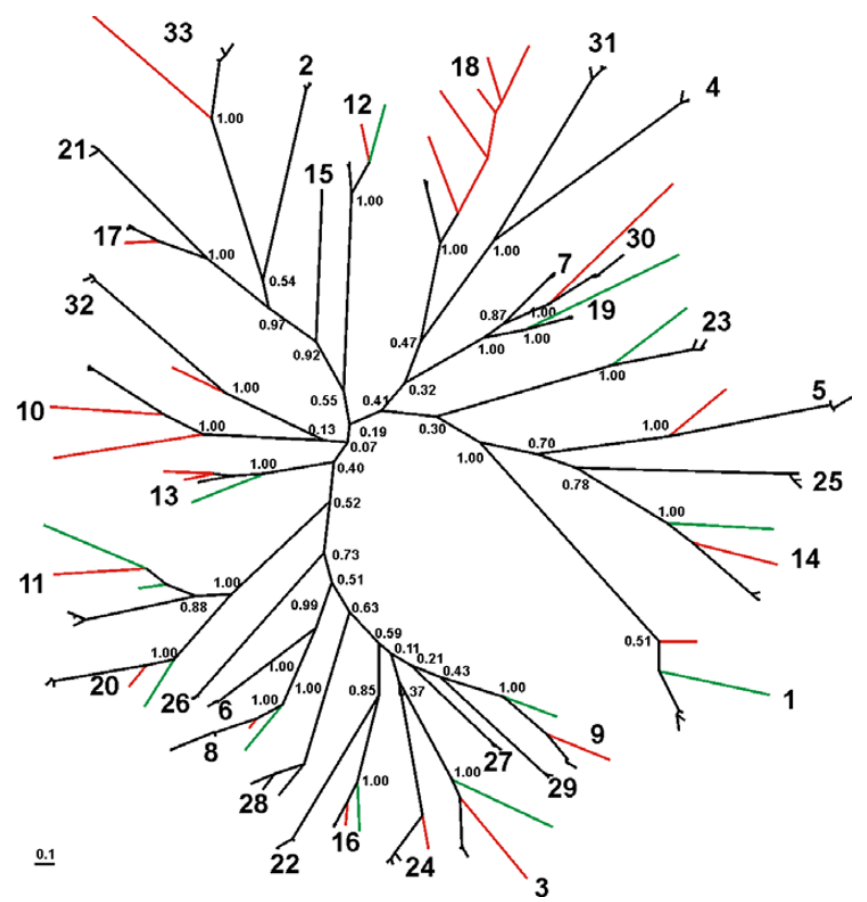

Figure 2

Unrooted bayesian phylogenetic tree of all C. elegans, C. briggsae, C. remanei, Brugia malayi (labeled in green) and Pristionchus pacificus (labeled in red) globins. The numbers at the nodes represent Bayesian posterior probabilities. The numbers at the branches are consistent with globin nomenclature in WormBase: ZK637.I 3 (I), C06E4.7 (2), C06H2.5 (3), C09HIO.8 (4), CI8C4.I (5), CI8C4.9 (6), C23H5.2 (7), C26C6.7 (8), C28F5.2 (9), C29F5.7 (I0), C36E8.2 (I I), C52AII.2 (I 2), FI9H6.2 (I3), F2 IA3.6 (I4), F35BI 2.8 (I5), F46C8.7 (I6), F49E2.4 (I7), F52A8.4 (I8), F56C4.3 (I9), R0IE6.6 (20), RI02.9 (2I), RIIH6.3 (22), RI3AI.8 (23), R90.5 (24), T06AI.3 (25), T22CI.2 (26), WOIC9.5 (27), Y I5E3A.2 (28), Y I7G7B.6 (29), Y22D7AR.5 (30), Y57G7A.9 (3I), Y58A7A.6 (32), Y75B7AL.I (33). ings refutes the possibility that some of them would be pseudogenes.

We also asked whether the large $\mathrm{N}$ - and C-terminal extensions of many C. elegans globins are required for their specific function. To this end we searched for positive selection on individual amino acids, because positive selection is thought to act only on specific residues in a protein that is under purifying selection [23]. No positive selection was detected using the maximum likelihood procedure of Thomas et al. [24,25], even in globin Y75B7AL.1, which is a chimeric polypeptide composed of a C-terminal globin domain and an N-terminal domain that has all characteristics of a G-coupled sensor. This domain contains 7 transmembrane helices and this structure is a candidate target for positive selection [25]. The strong purifying selection acting on the globin genes is consistent with the slowing of the rate of evolution of the exon-structures in the genus Caenorhabditis.

\section{Conclusion}

Our study unveils an unexpected complexity of the globin family in nematodes. Caenorhabditis species contain a very large number of globin genes, and even distantly related nematode species harbor orthologs to many of them. Our analysis provides some evidence for a number of gene duplication events giving rise to a class of globin genes that is likely unique to the nematode phylum. It remains to be seen whether this class will persist as more genomes will become available.

It is generally accepted that gene duplication played a major role in the evolution of eukaryotic genomes, particularly in the origin of multi-gene families [26]. Duplication events that gave rise to the radiation of nematode globin genes most likely occurred too long ago to leave behind obvious evidence of adaptive evolution. The dispersion of the globin genes over all six chromosomes of $C$. elegans is consistent with this idea. Globins R102.9 and F49E2.4 are exceptional in showing strong sequence conservation (Figure 2) and sharing 2 intron positions (Additional file 1). However, they are located on different chromosomes, arguing against a very recent tandem duplication event. Similarly, both C. briggsae orthologs are found on different chromosomes. 

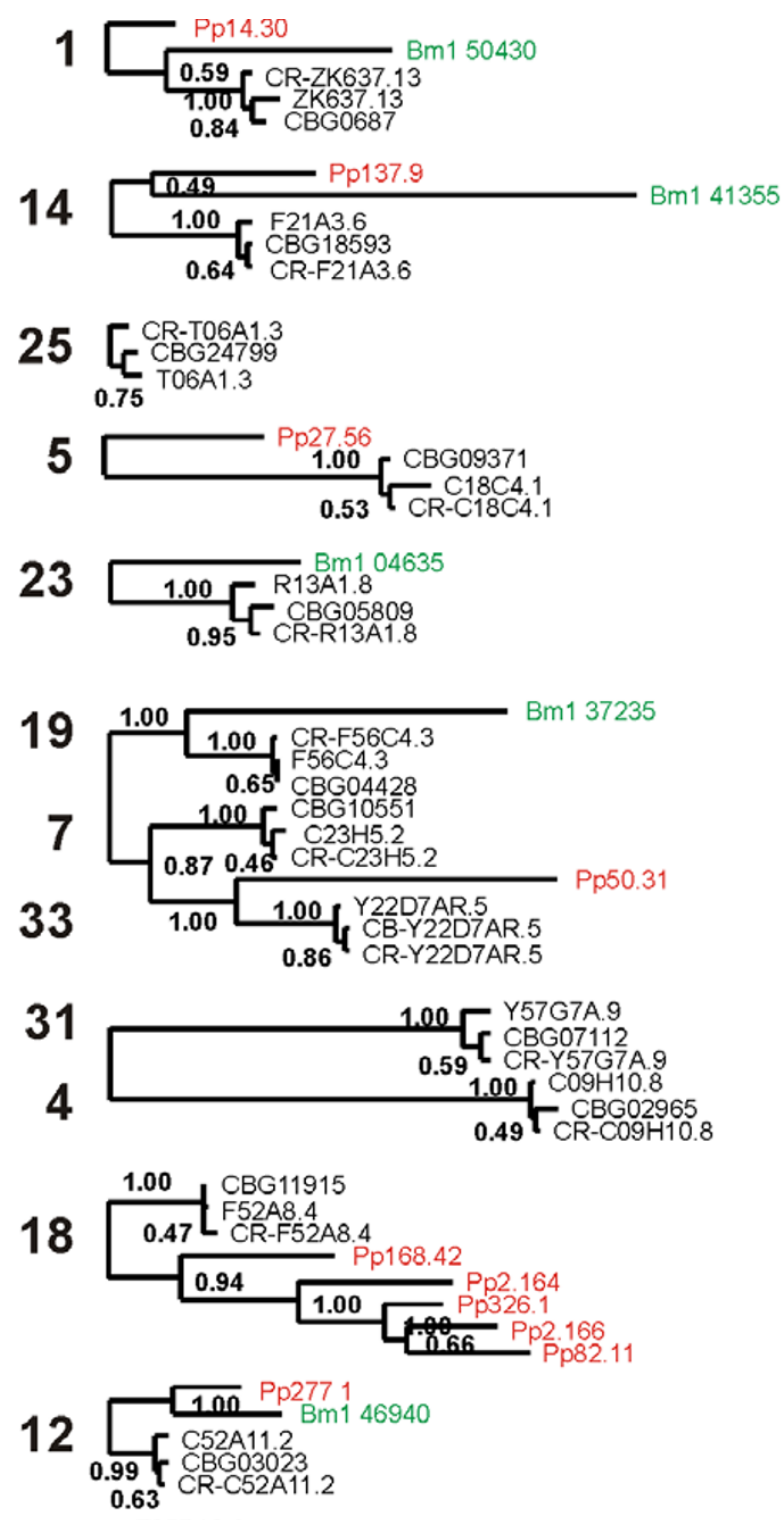

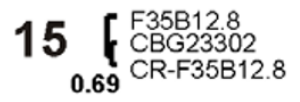

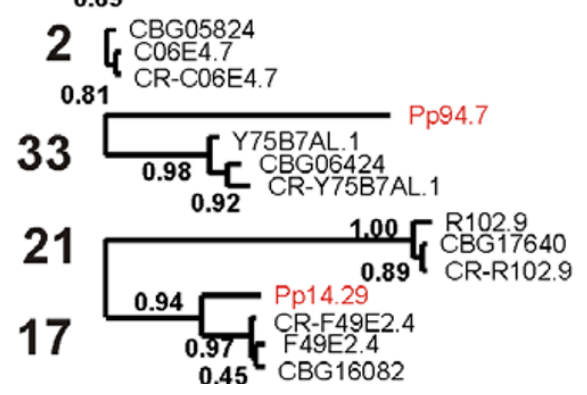

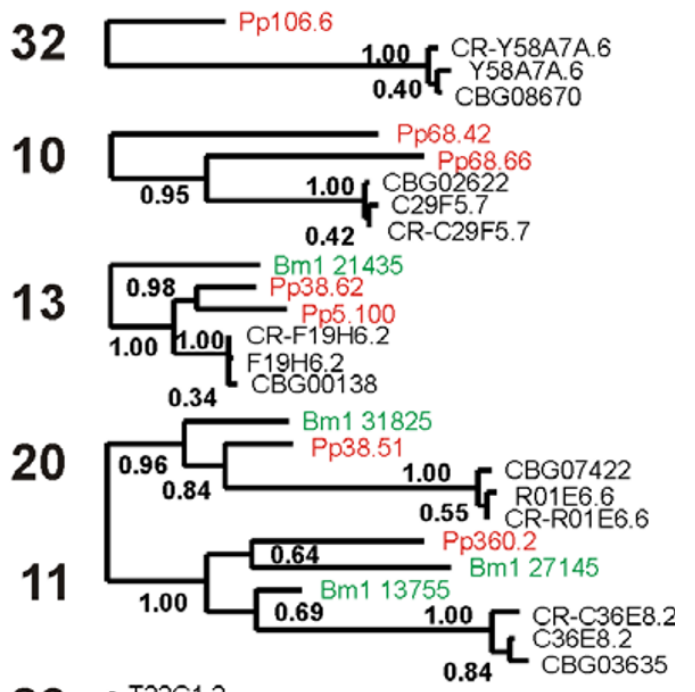
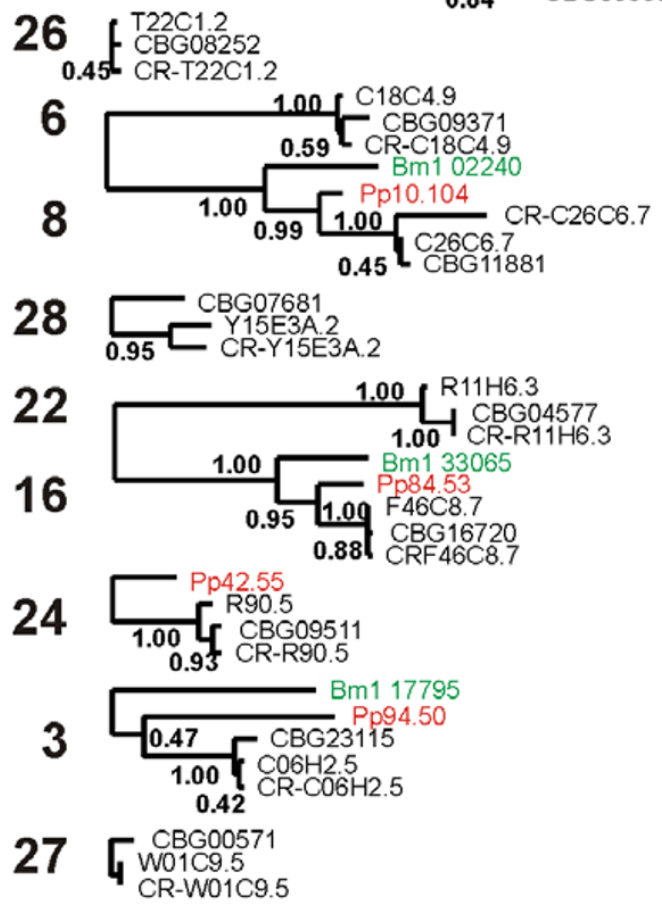

$29 \underset{\mathbf{0 . 3 6}}{2} \begin{gathered}\text { CR-Y17GTB } \\ \text { CBG21021 }\end{gathered}$

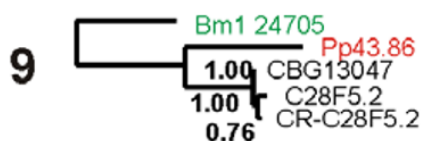

$\underline{0.1}$

Figure 3

Detailed view of Figure 2, phylogenetic relationship of all orthologous groups of $C$. elegans, $C$. briggsae, $C$. remanei, Brugia malayi (labeled in green) and Pristionchus pacificus (labeled in red) globins. Due to the complex WashU nomenclature ID, $C$. remanei globins are referred to as $C$. elegans homologue preceded by 'CR-'. The numbers at the nodes represent Bayesian posterior probabilities. 
Table 3: Overview of globin expression patterns

\begin{tabular}{|c|c|}
\hline Gene & Expression pattern \\
\hline C06E4.7 & Head neurons \\
\hline $\mathrm{C} 06 \mathrm{H} 2.5$ & Head and tail neurons, nerve cord \\
\hline $\mathrm{CO9HI0.8}$ & Head and tail neurons, nerve cord \\
\hline $\mathrm{Cl} 18 \mathrm{C} 4.1$ & Pharynx (Corpus, isthmus), head neurons, nerve cord \\
\hline C $18 C 4.9$ & Head and tail neurons, nerve cord \\
\hline $\mathrm{C} 23 \mathrm{H} 5.2$ & Head and tail neurons \\
\hline C26C6.7 & Body wall muscle \\
\hline C28F5.2 & Head and tail neurons, nerve cord, vulva neurons \\
\hline C29F5.7 & Head and tail neurons, nerve cord \\
\hline C36E8.2 & Pharynx (Corpus, terminal bulb), head and tail neurons, nerve cord \\
\hline C52AII.2 & Head and tail neurons \\
\hline $\mathrm{F} 19 \mathrm{H} 6.2$ & Head neurons, nerve cord, vulva neuron \\
\hline $\mathrm{F} 2 \mathrm{I} A 3.6$ & Head neurons, vulva neurons, vulval muscle \\
\hline $\mathrm{F} 35 \mathrm{~B} I 2.8$ & No observable expression \\
\hline F46C8.7 & Head neurons, tail neuron \\
\hline F49E2.4 & Head and tail neurons, nerve cord \\
\hline F52A8.4 & Head and tail neurons, nerve cord \\
\hline F56C4.3 & Head neurons and tail neuron \\
\hline R0IE6.6 & Stomato-intestinal muscle, depressor muscle, body wall muscle, head neurons, vulva neurons, nerve cord \\
\hline RI02.9 & Pharynx (Corpus), head neurons, nerve cord \\
\hline $\mathrm{RIIH6.3}$ & Head and tail neurons, nerve cord \\
\hline $\mathrm{R}|3 \mathrm{~A}| .8$ & Head neurons, nerve cord \\
\hline R90.5 & Head and tail neurons, nerve cord \\
\hline T06AI.3 & Head and tail neurons, nerve cord \\
\hline $\mathrm{T} 22 \mathrm{Cl} .2$ & Head mesodermal cell, stomato-intestinal muscle \\
\hline W0IC9.5 & Head and tail neurons, nerve cord \\
\hline YI5E3A.2 & Head and tail neurons, nerve cord \\
\hline YI7G7B.6 & Head and tail neurons, nerve cord \\
\hline Y22D7AR.5 & Head and tail neurons, nerve cord \\
\hline Y57G7A.9 & Head neurons \\
\hline Y58A7A.6 & Head and tail neurons, nerve cord \\
\hline Y75B7AL.I & Head and tail neurons, nerve cord \\
\hline ZK637.13 & Head muscle/hypodermis, tail muscle/hypodermis, head, tail and vulva neurons, Nerve cord \\
\hline
\end{tabular}

Why would tiny animals like Caenorhabditis species need up to 33 different globins? We have shown that they are all expressed and subject to strong purifying selection. Extensive gene duplication appears to be typical for Caenorhabditis. Other surprisingly large gene families include astacins [27], insulins [28], chemoreceptors [20,21] and orphan nuclear receptors HNF4 [29]. Subfunctionalization is frequently invoked to explain the retention of duplicate genes, and differences in gene expression patterns of duplicate genes are generally advanced in support of this hypothesis [30-33]. It is likely that this mechanism was the driving force for the expansion of the Caenorhabditis globin family. We have demonstrated that these genes are expressed in distinct subsets of cells and that they are subject to strong purifying selection, in line with this hypothesis. Further support is provided by differential expression of subsets of globin genes in the dauer stage and upon oxygen deprivation [7]. Evidence is mounting that behavioral responses of C. elegans to attracting or repelling chemicals including oxygen and $\mathrm{CO}_{2}$ are generated by gene activities that are deployed in different combinations of neurons [34-37]. Individual worm neurons seem to have attained very high specialization which is in keeping with their expressing unique or small subsets of globin isoforms.

To date the precise function of none of these globins is known. It seems unlikely that they would all be required for simple oxygen transportation or storage purposes. Globins that are upregulated when oxygen supply is low might serve this function [7]. Other functions are also plausible. It has been shown that C. elegans senses molecular oxygen through the heme domain of a guanylate cyclase homolog (GCY-35) and reacts rapidly to changing oxygen levels with aerotaxis responses $[37,38]$. We expect that some globins may play similar roles in distinct sensory neurons. One likely candidate is globin Y75B7AL.1 which has all characteristics of a G-coupled sensor. Still other functions are worth consideration. Globin T22C1.2 oxidizes instantly to the ferric form in the presence of oxygen and is therefore not capable of reversible oxygen binding (unpublished results). We speculate that this globin may participate in redox reactions with an as yet unidentified reaction partner. Alternatively, peroxidase activity 

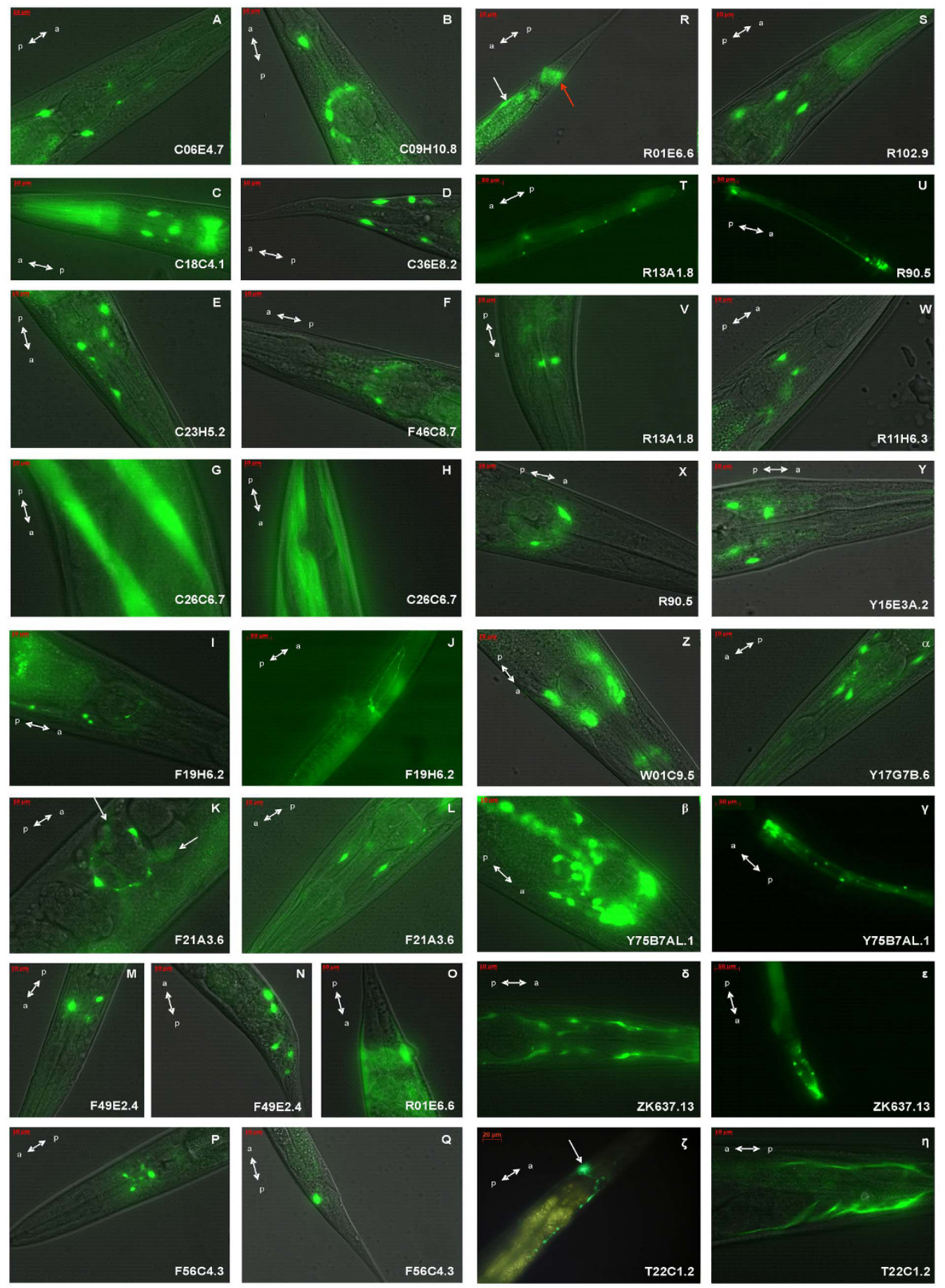

\section{Figure 4}

Expression patterns from a selected set of globin genes. A, anterior body part; P, posterior body part. (A) C06E4.7, (B) C09HI0.8, (C) Cl8C4.I, (D) C36E8.2, (E) C23H5.2, (F) F46C8.7, (G) C26C6.7, (H) C26C6.7, (I) FI9H6.2, (J) FI9H6.2, (K) F2I A3.6 white arrows denote vulval muscle, (L) F2 IA3.6, (M) F49E2.4, (N) F49E2.4, (O) R0IE6.6, (P) F56C4.3, (Q) F56C4.3, (R) R0IE6.6, white arrow denotes stomato-intestinal muscle, red arrow denotes anal depressor muscle, (S) R I02.9, (T) RI3AI.8, (U) R90.5, (V) RI3AI.8, (W) RIIH6.3, (X) R90.5, (Y) YI5E3A.2, (Z) W0IC9.5, ( $\alpha$ ) YI7G7B.6, ( $\beta$ ) Y75B7AL.I,

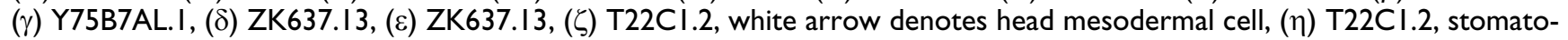
intestinal muscle. 
Table 4: Overview of intron insertion positions in the globin domain for all five-way conserved orthologs

\begin{tabular}{|c|c|c|c|c|c|}
\hline Globin & C. elegans & C. briggsae & C. remanei & B. malayi & P. pacificus \\
\hline $\mathrm{CO} 0 \mathrm{H} 2.5$ & A2.2 G15.0 & A2.2 GI5.0 & A2.2 GI5.0 & A2.2 BII.2 EFII $.0 \mathrm{HI} 6.0$ & AI5.0 BII.0 E9.I EFII.0 GI5.0 \\
\hline C26C6.7 & $\mathrm{C} 4.0 \mathrm{GH} 4.2$ & C4.0 GH4.2 & $\mathrm{C} 4.0 \mathrm{GH} 4.2$ & EI8.0 FGI.0 & BI.0 C4.0 El8.0 G2.I GH4.2 \\
\hline C28F5.2 & EI3.2 FG5.0 & EI3.2 FG5.0 & EI3.2 FG5.0 & C7.0 EI3.2 FG5.0 & AB9.I BI.0 C7.0 El3.2 F8.2 HI.0 \\
\hline C36E8.2 & $\mathrm{E} 6.0 \mathrm{EFI} 4.2 \mathrm{H} 22.2$ & $\mathrm{E} 6.0 \mathrm{EFI} 4.2 \mathrm{H} 22.2$ & $\mathrm{EF} 14.2 \mathrm{H} 22.2$ & E2.0 H8.2 & $\mathrm{E} 2.0 \mathrm{EFI} .0 \mathrm{H} 2 \mathrm{I} . \mathrm{I}$ \\
\hline C52AII.2 & $\mathrm{E} 18.0 \mathrm{FG} 2.2 \mathrm{GH} 2.0$ & El8.0 FG2.2 GH2.0 & E18.0 FG2.2 GH2.0 & Al4.0 C7.0 El8.0 GH6.0 & Al4.0 C7.0 El8.0 F7.0 GH6.0 HI0.2 \\
\hline FI9H6.2 & AB2.0 EI0.I HI2.0 & AB2.0 EI0.I HI2.0 & AB2.0 EI0.I HI2.0 & AB2.0 F3.0 HI 2.0 & A3.2 D6.2 F3.0 GI5.0 HI2.0 \\
\hline F2 IA3.6 & $\mathrm{B} 12.2 \mathrm{E} 5.2 \mathrm{G} 7.0$ & $\mathrm{~B} 12.2 \mathrm{E} 5.2 \mathrm{G} 7.0$ & BI2.2 E5.2 G7.0 & $\mathrm{B} 12.2 \mathrm{G} 7.0$ & BI2.2 EI7.0 G7.0 \\
\hline F46C8.7 & B9.0 F5.I & B9.0 F5.I & B9.0 F5.I & B9.0 EI0.0 F5.I HI9.0 & A7.0 B9.0 CD4.2 El0.0 F5.I GH2.I \\
\hline ROIE6.6 & B9.0 El6.0 HI.0 & B9.0 El6.0 HI.0 & B9.0 El6.0 HI.0 & C6.2 El6.0 HI.0 & B9.0 El6.0 FG2.I HI.0 \\
\hline ZK637.13 & E3.2 & E3.2 & E3.2 & BI2.2 EF2.I G7.0 & BI2.2 E3.2 EF7.0 G7.0 HI5.I \\
\hline
\end{tabular}

which is a latent but inherent property of globins might have evolved to become the ultimate function of other $C$. elegans globins. Finally, we cannot exclude a potential role as an alternative oxidase during anaerobiosis, when levels of oxygen drop below saturation of cytochrome oxidase, as has been well documented for plant cells $[39,40]$. Future research shall provide more answers.

\section{Methods}

Sequence database searches

The BLAST algorithm [8] was employed to search the sequence databases WormBase (Release WS182), TIGR (Brugia malayi) and http://www.pristionchus.org (Assembly Freeze 1). NEMBASE 3, containing EST clusters from 37 different partial parasitic nematode genomes [9], was searched for globin motifs (PF00041, PS01033 and SSF46458). Additional EST sequences were searched from EMBL-EBI parasite EST, and the NCBI parasite EST databases using the BLAST algorithm [8] with the Caenorhabditis globins as query sequences and cut off E-values of $e^{-}$ 05. In cases where the identification of a putative globin was uncertain, searches employing FUGUE [41] were used to determine whether the borderline sequence should be accepted as a globin.

Additional sequences of known nematode globins were obtained from GenBank: Trichostrongylus colubriformis (AA30102), Nippostrongylus brasiliensis cuticular globin (P51536), Nippostrongylus brasiliensis body wall globin (P51535),Toxocara canis body wall globin (AAL56428), Toxocara canis perienteric globin (吕56430), Ascaris suum myoglobin (AA464695), Ascaris suum hemoglobin
(AAA29374), Mermis nigrescens eye globin (AAF34874),Mermis nigrescens body wall globin (AAF35435), Syngamus trachea cuticular globin (AAL56426), Syngamus trachea body wall globin (AAL56427), Pseudoterranova decipiens (P26914). All encoded globin sequences were aligned manually as described previously $[42,43]$.

\section{Globin gene expression analysis}

The putative promoter and enhancer sequences upstream of the predicted start codon of each globin gene were extracted from the UCSC Genome Browser database using a repeat masker function [44]. PCR primers were designed to amplify about $3 \mathrm{~kb}$ of N2 wild-type genomic DNA, this size was reduced as needed to exclude any upstream gene located at a shorter distance. Promotor-GFP fusion constructs were generated as described by [45]. pRF4 rol6(su1006) plasmid and promoter-reporter fusion construct were co-injected at $100 \mathrm{ng} / \mu \mathrm{l}$ and $50 \mathrm{ng} / \mu \mathrm{l}$, respectively, into the gonads of young adult hermaphrodites. Rolling F1 worms were transferred to fresh plates and rolling F2 progeny were examined for fluorescence using an Axiovert $200 \mathrm{M}$ (Zeiss) fluorescence microscope. At least 2 independent transgenic lines were examined for each globin gene. These lines generally displayed very similar GFP expression patterns. Primer sequences are available upon request.

\section{Pairwise estimates of $K_{A}$ and $K_{S}$}

After manual alignment of orthologous briggsae/elegans globin pairs, alignments of corresponding coding sequences were used to calculate the ratios $(\omega)$ of non- 


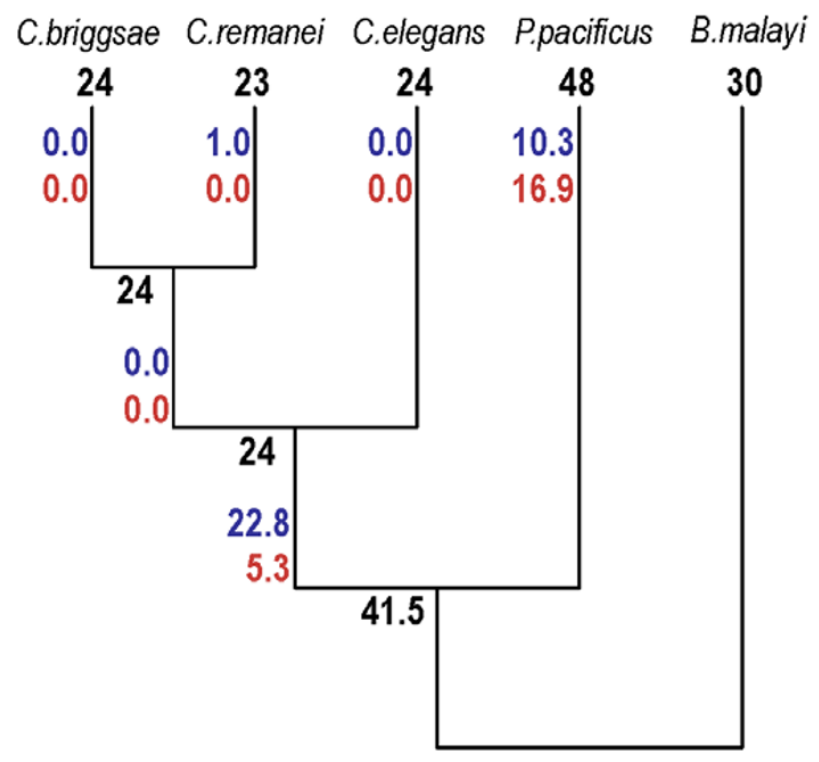

Number of introns
Losses
Gains

\section{Figure 5}

Estimates of intron losses and gains.

synonymous $\left(K_{\mathrm{A}}\right)$ to synonymous substitutions $\left(K_{\mathrm{S}}\right)$. We used the Yang and Nielsen [46] maximum likelihood method implemented in the YN00 program of the PAML package version 3.15 [47] since the Nei and Gojobori [48] method was not applicable in some cases. Similar results were generated in cases where both methods were applicable.

\section{Phylogenetic analysis}

Bayesian inference trees were obtained employing MrBayes version 3.1.2 [49]; four chains were run simultaneously for $4 \times 10^{6}$ generations and trees were sampled every 100 generations generating a total of 40000 trees. The final average standard deviations of split frequencies were stationary and in the range of about 0.016 . Posterior probabilities were estimated on the final 30000 trees. The appropriate model of amino acid sequence evolution (JTT model [50]) was selected by ProtTest [51] using the Akaike Information Criterion (AIC).

\section{Authors' contributions}

DH and JRV conceived and designed the study; DH and SDH carried out data collection and genomic analysis and generated fusion constructs; $\mathrm{DH}$ and $\mathrm{MC}$ performed micro-injection experiments; $\mathrm{DH}$ and SWR performed data analysis; SD, LM, GB and SNV provided additional input in data analysis; DH, SWR and JRV wrote the man-
Table 5: Overview of $K_{A} / K_{S}(\omega)$-ratios for $C$. briggsae - C. elegans orthologs

\begin{tabular}{|c|c|}
\hline globin & $K_{A} / K_{S}$ \\
\hline C06E4.7 & 0.0171 \\
\hline $\mathrm{CO} 6 \mathrm{H} 2.5$ & 0.0184 \\
\hline СО9HIO.8 & 0.0115 \\
\hline Cl8C4.I & 0.0248 \\
\hline $\mathrm{Cl} 8 \mathrm{C} 4.9$ & 0.0295 \\
\hline $\mathrm{C} 23 \mathrm{H} 5.2$ & 0.0376 \\
\hline$C 26 C 6.7$ & 0.0223 \\
\hline C28F5.2 & 0.0199 \\
\hline C29F5.7 & 0.0172 \\
\hline C36E8.2 & 0.0519 \\
\hline C52AII.2 & 0.0400 \\
\hline FI9H6.2 & 0.0096 \\
\hline F2IA3.6 & 0.0535 \\
\hline$F 35 B / 2.8$ & 0.0070 \\
\hline$F 46 C 8.7$ & 0.0260 \\
\hline F49E2.4 & 0.0178 \\
\hline F52A8.4 & 0.0318 \\
\hline F56C4.3 & 0.0274 \\
\hline ROIE6.6 & 0.0473 \\
\hline R/02.9 & 0.0344 \\
\hline $\mathrm{R} / \mathrm{IH} 6.3$ & 0.0251 \\
\hline$R / 3 A \mid .8$ & 0.0372 \\
\hline R90.5 & 0.0292 \\
\hline T06A I.3 & 0.0381 \\
\hline$T 22 \mathrm{Cl} .2$ & 0.0506 \\
\hline Wolc9.5 & 0.0153 \\
\hline YI5E3A.2 & 0.1876 \\
\hline YI 7G7B.6 & 0.0173 \\
\hline Y22D7AR.5 & 0.0287 \\
\hline Y57G7A.9 & 0.0274 \\
\hline Y58A7A.6 & 0.0093 \\
\hline Y75B7AL.I & 0.1102 \\
\hline ZK637.13 & 0.0849 \\
\hline
\end{tabular}

uscript. All authors read and approved the final manuscript.

\section{Additional material}

\section{Additional file 1}

Overview of intron insertion positions in Caenorhabditis, Brugia malayi and Pristionchus pacificus globins. Identical Caenorhabditis-Pristionchus intron positions are marked in red, identical BrugiaPristionchus intron postions in blue and identical Brugia-Caenorhabditis intron postions in green. Phase 0 introns separate two consecutive codons (annotated by the number of the amino acid residue, a dot and number 0). Phase 1 and phase 2 introns are inserted following the first or second base of a codon, respectively (annotated by the number of the amino acid, a dot and number 1 or 2, respectively). Introns inserted in the $N$-terminal extensions are referred to as NA counting from amino acid 1 , $H C$ for those inserted in the C-terminal extension starting with the first amino acid after the H-helix.

Click here for file

[http://www.biomedcentral.com/content/supplementary/14712148-8-279-S1.doc] 


\author{
Additional file 2 \\ Manual alignment of nematode globins. \\ Click here for file \\ [http://www.biomedcentral.com/content/supplementary/1471- \\ 2148-8-279-S2.doc]

\section{Additional file 3} \\ Similarity matrix of all 33 C. elegans globins based on the alignment \\ provided in Additional file 2. \\ Click here for file \\ [http://www.biomedcentral.com/content/supplementary/1471- \\ 2148-8-279-S3.xls]

\section{Additional file 4} \\ Unrooted bayesian trees based on matrices of five-way orthologs from $\mathrm{C}$. \\ elegans, C. briggsae, C. remanei, Pristionchus pacificus and Brugia \\ malayi. glb globin; gst glutathione S-transferase; ast astacin, sod super- \\ oxide dismutase, acr nicotinic acetylcholine receptors; wrt hedgehog- \\ related (warthog) proteins; abc ATP-binding proteins. \\ Click here for file \\ [http://www.biomedcentral.com/content/supplementary/1471- \\ 2148-8-279-S4.jpeg]
}

\section{Acknowledgements}

We thank Yves Van de Peer for critical reading of the manuscript and Guy Haegeman for use of the fluorescence microscope. This work was supported by grants from the Fund for Scientific Research Flanders (G.033I.04). SD is a postdoctoral fellow of the Fund for Scientific Research Flanders (FWO).

\section{References}

I. Burmester T, Weich B, Reinhardt S, Hankeln T: A vertebrate globin expressed in the brain. Nature 2000, 407(6803):520-523.

2. Burmester T, Ebner B, Weich B, Hankeln T: Cytoglobin: a novel globin type ubiquitously expressed in vertebrate tissues. Mol Biol Evol 2002, I 9(4):416-42I.

3. Weber RE, Vinogradov SN: Nonvertebrate hemoglobins: functions and molecular adaptations. Physiol Rev 200I, 8 I(2):569-628.

4. Vinogradov SN, Moens L: Diversity of globin function: Enzymatic, transport, storage and sensing. J Biol Chem 2008, 283:8773-8777.

5. Blaxter ML: Nemoglobins: divergent nematode globins. Parasitol Today 1993, 9(10):353-360.

6. Hoogewijs D, Geuens E, Dewilde S, Moens L, Vierstraete A, Vinogradov S, Vanfleteren J: Genome-wide analysis of the globin gene family of C. elegans. IUBMB Life 2004, 56( I I- I 2):697-702.

7. Hoogewijs D, Geuens E, Dewilde S, Vierstraete A, Moens L, Vinogradov S, Vanfleteren JR: Wide diversity in structure and expression profiles among members of the Caenorhabditis elegans globin protein family. BMC Genomics 2007, 8:356.

8. Altschul SF, Madden TL, Schaffer AA, Zhang J, Zhang Z, Miller W, Lipman DJ: Gapped BLAST and PSI-BLAST: a new generation of protein database search programs. Nucleic Acids Res 1997, 25(I 7):3389-3402.

9. Parkinson J, Whitton C, Schmid R, Thomson M, Blaxter M: NEMBASE: a resource for parasitic nematode ESTs. Nucleic Acids Res 2004:D427-430.

10. Blaxter ML, De Ley P, Garey JR, Liu LX, Scheldeman P, Vierstraete A, Vanfleteren JR, Mackey LY, Dorris M, Frisse LM, Vida JT, Thomas WK: A molecular evolutionary framework for the phylum Nematoda. Nature 1998, 392(667I):7I-75.

II. Meldal BH, Debenham NJ, De Ley P, De Ley IT, Vanfleteren JR, Vierstraete AR, Bert W, Borgonie G, Moens T, Tyler PA, Austen MC, Blaxter ML, Rogers AD, Lambshead PJ: An improved molecular phylogeny of the Nematoda with special emphasis on marine taxa. Mol Phylogenet Evol 2007, 42(3):622-636.

12. Dunn CW, Hejnol A, Matus DQ, Pang K, Browne WE, Smith SA, Seaver E, Rouse GW, Obst M, Edgecombe GD, Sorensen MV, Haddock SH, Schmidt-Rhaesa A, Okusu A, Kristensen RM, Wheeler WC, Martindale MQ, Giribet G: Broad phylogenomic sampling improves resolution of the animal tree of life. Nature 2008, 452(71 88): $745-749$.

13. Tamura K, Dudley J, Nei M, Kumar S: MEGA4: Molecular Evolutionary Genetics Analysis (MEGA) software version 4.0. Mol Biol Evol 2007, 24(8): 1596-1599.

14. Stamatakis A, Hoover P, Rougemont J: A Rapid Bootstrap Algorithm for the RAxML Web-Servers. Syst Biol 2008 in press.

15. Stein LD, Bao Z, Blasiar D, Blumenthal T, Brent MR, Chen N, Chinwalla A, Clarke L, Clee C, Coghlan A, Coulson A, D'Eustachio P, Fitch DH, Fulton LA, Fulton RE, Griffiths-Jones S, Harris TW, Hillier LW, Kamath R, Kuwabara PE, Mardis ER, Marra MA, Miner TL, Minx P, Mullikin JC, Plumb RW, Rogers J, Schein JE, Sohrmann M, Spieth J, Stajich JE, Wei C, Willey D, Wilson RK, Durbin R, Waterston RH: The genome sequence of Caenorhabditis briggsae : a platform for comparative genomics. PLoS Biol 2003, I(2): E45.

16. Kent WJ, Zahler AM: Conservation, regulation, synteny, and introns in a large-scale $C$. briggsae- $C$. elegans genomic alignment. Genome Res 2000, I0(8): III5-II 25.

17. Roy SW, Gilbert W: Rates of intron loss and gain: implications for early eukaryotic evolution. Proc Natl Acad Sci USA 2005, 102(16):5773-5778.

18. Roy SW, Gilbert W: Complex early genes. Proc Natl Acad Sci USA 2005, 102(6): 1986-199|.

19. Kiontke K, Gavin NP, Raynes Y, Roehrig C, Piano F, Fitch DH: Caenorhabditis phylogeny predicts convergence of hermaphroditism and extensive intron loss. Proc Natl Acad Sci USA 2004, I0I(24):9003-9008.

20. Robertson HM: Two large families of chemoreceptor genes in the nematodes Caenorhabditis elegans and Caenorhabditis briggsae reveal extensive gene duplication, diversification, movement, and intron loss. Genome Res 1998, 8(5):449-463.

21. Robertson HM: The large srh family of chemoreceptor genes in Caenorhabditis nematodes reveals processes of genome evolution involving large duplications and deletions and intron gains and losses. Genome Res 2000, 10(2): 192-203.

22. Roy SW, Penny D: Smoke without fire: most reported cases of intron gain in nematodes instead reflect intron losses. Mol Biol Evol 2006, 23( I 2):2259-2262.

23. Nielsen R, Yang Z: Likelihood models for detecting positively selected amino acid sites and applications to the HIV-I envelope gene. Genetics 1998, 148(3):929-936.

24. Thomas JH: Adaptive evolution in two large families of ubiquitin-ligase adapters in nematodes and plants. Genome Res 2006, 16(8): $1017-1030$.

25. Thomas JH, Kelley JL, Robertson HM, Ly K, Swanson WJ: Adaptive evolution in the SRZ chemoreceptor families of Caenorhabditis elegans and Caenorhabditis briggsae. Proc Natl Acad Sci USA 2005, 102(I2):4476-448I.

26. Lespinet $\mathrm{O}$, Wolf $\mathrm{YI}, \mathrm{Koonin} \mathrm{EV}$, Aravind L: The role of lineagespecific gene family expansion in the evolution of eukaryotes. Genome Res 2002, I 2(7): 1048-1059.

27. Mohrlen $F$, Hutter $H$, Zwilling R: The astacin protein family in Caenorhabditis elegans. EurJ Biochem 2003, 270(24):4909-4920.

28. Pierce SB, Costa M, Wisotzkey R, Devadhar S, Homburger SA, Buchman AR, Ferguson KC, Heller J, Platt DM, Pasquinelli AA, Liu LX, Doberstein SK, Ruvkun G: Regulation of DAF-2 receptor signaling by human insulin and ins- I, a member of the unusually large and diverse $C$. elegans insulin gene family. Genes Dev 200I, I 5(6):672-686

29. Robinson-Rechavi M, Maina CV, Gissendanner CR, Laudet V, Sluder $A$ : Explosive lineage-specific expansion of the orphan nuclear receptor HNF4 in nematodes. J Mol Evol 2005, 60(5):577-586.

30. Cusack BP, Wolfe KH: When gene marriages don't work out: divorce by subfunctionalization. Trends Genet 2007, 23(6):270-272.

3I. Freilich S, Massingham T, Blanc E, Goldovsky L, Thornton JM: Relating tissue specialization to the differentiation of expression of singleton and duplicate mouse proteins. Genome Biol 2006, 7(10): R89. 
32. Fuchs C, Luckhardt A, Gerlach F, Burmester T, Hankeln T: Duplicated cytoglobin genes in teleost fishes. Biochem Biophys Res Commun 2005, 337(I):216-223.

33. Lynch M, Force $A$ : The probability of duplicate gene preservation by subfunctionalization. Genetics 2000, I 54 (I):459-473.

34. Chang AJ, Bargmann Cl: Hypoxia and the HIF-I transcriptional pathway reorganize a neuronal circuit for oxygen-dependent behavior in Caenorhabditis elegans. Proc Natl Acad Sci USA 2008, I 05(20):732I-7326.

35. Hallem EA, Sternberg PW: Acute carbon dioxide avoidance in Caenorhabditis elegans. Proc Natl Acad Sci USA 2008, 105(23):8038-8043.

36. Bretscher AJ, Busch KE, de Bono M: A carbon dioxide avoidance behavior is integrated with responses to ambient oxygen and food in Caenorhabditis elegans. Proc Natl Acad Sci USA 2008 1 05(23):8044-8049.

37. Cheung BH, Cohen M, Rogers C, Albayram O, de Bono M: Experience-dependent modulation of $C$. elegans behavior by ambient oxygen. Curr Biol 2005, I 5( I 0):905-917.

38. Gray JM, Karow DS, Lu H, Chang AJ, Chang JS, Ellis RE, Marletta MA, Bargmann $\mathrm{Cl}$ : Oxygen sensation and social feeding mediated by a C. elegans guanylate cyclase homologue. Nature 2004 , 430(6997):317-322

39. Igamberdiev AU, Hill RD: Nitrate, NO and haemoglobin in plant adaptation to hypoxia: an alternative to classic fermentation pathways. J Exp Bot 2004, 55(408):2473-2482.

40. Igamberdiev AU, Hill RD: Plant Mitochondrial Function During Anaerobiosis. Ann Bot (Lond) 2008.

4I. FUGUE [http://tardis.nibio.go.jp/fugue/]

42. Vinogradov SN, Hoogewijs D, Bailly X, Arredondo-Peter R, Guertin M, Gough J, Dewilde S, Moens L, Vanfleteren JR: Three globin lineages belonging to two structural classes in genomes from the three kingdoms of life. Proc Natl Acad Sci USA 2005, I 02(32): I I385- I I 389.

43. Vinogradov SN, Hoogewijs D, Bailly X, Arredondo-Peter R, Gough J, Dewilde S, Moens L, Vanfleteren JR: A phylogenomic profile of globins. BMC Evol Biol 2006, 6:31.

44. UCSC Genome Browser [http://genome.ucsc.edu/]

45. Hobert O: PCR fusion-based approach to create reporter gene constructs for expression analysis in transgenic $C$. elegans. Biotechniques 2002, 32(4):728-730.

46. Yang Z, Nielsen R: Estimating synonymous and nonsynonymous substitution rates under realistic evolutionary models. Mol Biol Evol 2000, 17(1):32-43.

47. Yang Z: PAML: a program package for phylogenetic analysis by maximum likelihood. Comput Appl Biosci 1997, 13(5):555-556.

48. Nei M, Gojobori T: Simple methods for estimating the numbers of synonymous and nonsynonymous nucleotide substitutions. Mol Biol Evol I 986, 3(5):418-426.

49. Huelsenbeck JP, Ronquist F: MRBAYES: Bayesian inference of phylogenetic trees. Bioinformatics 200I, I7(8):754-755.

50. Jones DT, Taylor WR, Thornton JM: The rapid generation of mutation data matrices from protein sequences. Comput Appl Biosci 1992, 8(3):275-282.

5I. Abascal F, Zardoya R, Posada D: ProtTest: selection of best-fit models of protein evolution. Bioinformatics 2005, 2I(9):2104-2105.
Publish with Bio Med Central and every scientist can read your work free of charge

"BioMed Central will be the most significant development for disseminating the results of biomedical research in our lifetime. "

Sir Paul Nurse, Cancer Research UK

Your research papers will be:

- available free of charge to the entire biomedical community

- peer reviewed and published immediately upon acceptance

- cited in PubMed and archived on PubMed Central

- yours - you keep the copyright
BioMedcentral 